Article

\title{
External Robotic Arm vs. Upper Limb Exoskeleton: What Do Potential Users Need?
}

\author{
Hyung Seok Nam ${ }^{1,2}{ }^{\mathbb{D}}$, Han Gil Seo ${ }^{2} \mathbb{D}$, Ja-Ho Leigh ${ }^{2}$, Yoon Jae Kim ${ }^{3}$, Sungwan Kim ${ }^{1,4} \mathbb{D}^{\mathbb{D}}$ and \\ Moon Suk Bang 2,5,*iD \\ 1 Department of Biomedical Engineering, Seoul National University College of Medicine, Seoul 03080, Korea; \\ ignite31@snu.ac.kr (H.S.N.); sungwan@snu.ac.kr (S.K.) \\ 2 Department of Rehabilitation Medicine, Seoul National University Hospital, Seoul 03080, Korea; \\ hangilseo@snu.ac.kr (H.G.S.); mazican@snu.ac.kr (J.-H.L.) \\ 3 Interdisciplinary Program for Bioengineering, Seoul National University Graduate School, Seoul 08826, \\ Korea; yoonjaekim@snu.ac.kr \\ 4 Institute of Medical and Biological Engineering, Seoul National University, Seoul 03080, Korea \\ 5 Department of Rehabilitation Medicine, Seoul National University College of Medicine, Seoul 03080, Korea \\ * Correspondence: msbang@snu.ac.kr; Tel.: +82-2-2072-2619
}

Received: 22 April 2019; Accepted: 13 June 2019; Published: 17 June 2019

Featured Application: This study is an investigation of the practical demands of potential users of assistive rehabilitation robots from a survey performed in patients with functional upper limb impairments. While the development of simple and practical robots is becoming more important, this research will serve as a valuable reference in further developments.

\begin{abstract}
Robotic devices that practically assist activities of daily living (ADL) are scarce. The aim of this study was to investigate practical demands of potential users of external robotic arms and upper limb exoskeletons for assistance in ADL. A survey was performed in rehabilitation clinics in individuals with functional impairments in the upper extremity, divided into unilateral (UIG, $n=24$ ) and bilateral impairment groups (BIG, $n=24)$. Descriptive analyses were performed for current dependency, objective importance, and subjective necessity of the 18 ADLs by using a 5-point Likert scale. Overall, handling foods, dressing, and moving close items were highly necessary functions for both robot types. The UIG demonstrated a high demand for self-exercise using exoskeletons, whereas one-hand ADLs showed low necessity. In the UIG, the exoskeleton had significantly higher demands than the external robotic arm in washing face $(p=0.005)$ and brushing teeth $(p=0.007)$. The subjects in the BIG replied that cleaning desks and eating are highly necessary abilities for the external robotic arm; and transfer and wheelchair control, for exoskeletons. In the BIG, the exoskeleton showed significantly higher necessity than the external robotic arms in dressing $(p=0.010)$, making phone calls $(p=0.026)$, using a smartphone $(p=0.011)$, and writing $(p=0.005)$. The practical demands of potential users were affected by laterality and robot type. Further robot developments should involve essential functions based on the survey results to meet end-user needs.
\end{abstract}

Keywords: brain-computer interfaces; robotics; exoskeleton; patient demand; activities of daily living

\section{Introduction}

Since the early 2000s, various types of robots and robotic devices have entered the field of rehabilitation [1-3]. Rehabilitation robots such as InMotion or Armeo Power for the upper extremity and Lokomat for the lower extremity, are the main examples of widely used robots for the purpose of treatment in a hospital setting [4-8]. For use outside the hospital, some of the lower extremity robots such as ReWalk, EKSO, and HAL, are being used by the persons with functional impairments despite 
their relatively high cost $[9,10]$. However, to our knowledge, no specific robot has been commercially and widely utilized to assist in performing activities of daily living (ADL) that require the upper extremities, although some are being used in limited circumstances [11].

Robots used for only treatment purposes are fixed at a certain location in the hospital, and do not require portability in that setting. Robots to be used in a daily setting should be simple, portable, applicable to real objects rather than virtual reality forms or computer screens, and controllable according to the user's intent. For extraction of the user's intent, some of the most common modalities utilized by developers are force or torque sensors, and surface electromyography [12]. However, persons with severe impairment or near-complete paralysis cannot provide sufficient movement to generate input signals to those sensors. Currently, brain-machine interfaces (BMI) are being focused on as an eventual tool to directly assess user intent. However, non-invasive brain signals such as electroencephalography signals exhibit a low signal-to-noise ratio, which hinders precise control. Furthermore, invasive brain signals such as electrocorticography and signals from intracortical microelectrodes still need further development for use in an everyday setting [13-15]. Therefore, the purpose of the robot in the development and design stage must be clarified to simplify and adapt the robot structure, including whether it needs to be in a form of an external robotic arm or exoskeleton, so that it may be practically applied in ADL with simple control modalities. To clarify the purpose, the practical demands of the potential users with functional impairment needs to be evaluated to avoid a situation where a perfect robot for both control and function is developed but nobody seeks to use it.

In this study, the research question was which ADLs are mostly in demand for potential users of the robot in terms of necessity for robotic assistance. We hypothesized that there would exist specific ADLs with more priority to the potential users and that it would differ according to the type of the robot and laterality of the impairment. The type of the assistive robot was classified into two types, an external robotic arm type and an exoskeleton type. The external robotic arm type was defined as a robotic device controlled by one or more motors that is not wearable by a human and fixed on a table or a wheelchair. JACO and iARM are two of the most popular external robotic arms [3]. The exoskeleton type was defined as a robot device controlled by one or more motors, that is wearable on a human body either in the upper or lower extremity and in a portable form, corresponding to anatomical joints of the human body while structural modifications are permitted. The end-effector type robots were excluded because they generally do not provide assistive functions. The aim of this study was to investigate the practical demands of potential users of the assistive robots, specifically for both the external robotic arm and upper limb exoskeleton, and also analyze the differences between them.

\section{Materials and Methods}

\subsection{Survey Development and ADL Items}

For differentiation of utilizing the external robotic arm and upper limb exoskeleton for assistance, it was defined and explained to the survey participants that the external robotic arm will assist as a helper external to the body performing the desired movement or providing and placing the object that is needed for completing the task. It was described that the exoskeleton would be in a completely wearable form to assist the movements of the paralyzed part of the body, including the fingers in the form of a glove. For control of the robot, the subjects were asked to assume a perfect BMI control system and a robot that could perform all of the tasks completely. The subjects were informed about the three categories of BMI technology from non-invasive to invasive to have a concept of BMI; however, for the survey, they were instructed to assume the best BMI system without significant risks. Regarding each different task, it was assumed that the robot was specifically designed for the designated ADL task; therefore, a robot for assisting eating and another robot for assisting brushing teeth may have different forms of hardware and control mechanisms regardless of the total degree of freedom of the robot. It was also assumed that a robot hand or a glove type exoskeleton with precise control is mounted on 
the robot. They were instructed not to take realizability into consideration, but rather to focus on the importance and necessity of the ADL items themselves.

Fourteen ADLs were selected for rating in regard to both the external robotic arm and upper limb exoskeleton, and four additional items were selected for exoskeletons. The survey items were extracted from the commonly used ADL assessment tools, such as the modified Barthel Index (MBI) [16] or Functional Independence Measure (FIM) [17], as well as some results from our preliminary research. After the extraction, a professional committee meeting that consisted of four physiatrists, two rehabilitation robot engineers, and two neuroscience engineers reviewed the survey items and selected relevant survey items. The 14 selected ADL items were as follows: (1) washing face, (2) brushing teeth (including squeezing toothpaste), (3) hairdressing (handling hair and combing), (4) dressing (putting on or taking off clothes), (5) eating (using utensils such as spoon or fork, and bringing them to their mouths), (6) handling foods (i.e., peeling a banana, opening a bottle cap, etc.), (7) cleaning (cleaning one's desk), (8) moving close items (from one place to another on a desk or a table), (9) using a smartphone (using a smartphone or smart tablet, including holding the device with one hand and manipulation of the screen with the other hand), (10) using a computer (using a computer, more focusing on using the keyboard), (11) making phone calls (dialing and receiving a phone call), (12) writing, (13) switch control, and (14) using a purse (putting in and taking out bills and cards from a purse/wallet). The four additional items for exoskeletons were as follows: (1) transfer (assisting bed to chair, chair to standing, etc.), (2) toilet use (hygiene process), (3) self-exercise (range-of-motion exercises of the upper extremity), and (4) wheelchair control (both manual and electric). These items were not included for the external robotic arm category and considered not appropriate to be assisted by an external robot, and the assistance method was clearly explained to the survey participants. The survey form and detailed instructions are provided in the Appendix A.

\subsection{Participants}

The survey was conducted among volunteers with severe functional impairments of either the unilateral or bilateral upper extremities caused by various neuromuscular diseases, who are considered to be potential users of the external robotic arm or upper limb exoskeleton controlled by a BMI system upon its development. A total of 48 patients from the outpatient clinic of the Department of Rehabilitation in Seoul National University Hospital, Korea, volunteered to answer the survey. All the participants provided written, informed consent before enrollment. This study was approved by the Institutional Review Board of Seoul National University Hospital (IRB No. 1505-017-668, date of approval: 20 May 2015).

\subsection{Procedure}

For each ADL selected, all the participants were asked to rate their current level of dependence on another person by using a 5-point Likert scale (1: totally dependent, 2: mostly dependent; 3 : moderately dependent; 4: mostly independent, 5 : totally independent). Then, the participant rated the objective importance of the function from the viewpoint of a developer based on their experience with severe functional impairment. External robotic device and exoskeletons were rated separately, also using a 5-point Likert scale (1: unimportant; 2: of little importance; 3: moderately important; 4: important; 5: very important). The same items were presented to determine the subjective necessity of the function from the viewpoint of a consumers based on their current daily activities. They were asked if they would need to use it if a perfect robot with the mentioned function was provided (1: not necessary, 2: of little necessity, 3: moderately necessary, 4: necessary, 5: highly necessary). A short free interview was conducted after the survey to assess detailed information on their answers.

\subsection{Statistical Analysis}

The mean rating scores for the dependency of each survey item were calculated to establish the order of dependent ADL items, for UIG and BIG groups, respectively. The proportion of each response 
was calculated for the importance and necessity of each ADL item in both groups. Mann-Whitney tests for comparison of necessity between the UIG and BIG regarding each ADL items were performed for each type of robot. Wilcoxon signed rank tests were performed to compare the necessity of each item between the two types of robotic devices in each impairment group. All statistical analyses were performed using SPSS v21.0 (SPSS Inc., Chicago, IL, USA). A $p$ value of less than 0.05 was considered statistically significant.

\section{Results}

\subsection{Demographic Data}

A total of 48 subjects ( 42 men and six women) participated in the survey. Their mean age was $42.6 \pm 22.2$ years, and the mean duration since onset was $99.7 \pm 54.7$ months. All the subjects in the unilateral impairment group (UIG, $n=24$ ) had chronic stroke and no functional use of the hemiplegic arm, whereas no significant impairments of the contralateral arm were observed. The BIG $(n=24)$ consisted of patients with cervical spinal cord injury $(n=5)$, Duchenne muscular dystrophy $(n=18)$, and amyotrophic lateral sclerosis $(n=1)$. Half of the subjects $(n=12)$ reported partial functional use of at least one upper extremity, and the other half $(n=12)$ reported no functional use of both upper extremities. Detailed demographic data of the subgroups are shown in Table 1.

Table 1. Demographic data of survey participants.

\begin{tabular}{lccc}
\hline \multicolumn{1}{c}{ Data } & Unilateral Impairment Group & Bilateral Impairment Group & Total \\
\hline No. of subjects & 24 & 24 & 48 \\
$\quad$ Chronic stroke & 24 & 5 & \\
Cervical spinal cord injury & & 18 & \\
$\quad$ Duchenne muscular dystrophy & & 1 & $42: 6$ \\
$\quad$ Amyotrophic lateral sclerosis & $20: 4$ & $22: 2$ & $42.6 \pm 22.2$ \\
Male:Female $(n)$ & $61.2 \pm 5.3$ & $24.8 \pm 17.0$ & $99.7 \pm 54.6$ \\
Average age (years) & $109.5 \pm 51.8$ & $90.1 \pm 56.7$ & \\
Average duration since onset (months) & & & \\
\hline
\end{tabular}

\subsection{Unilateral Impairment Group}

In the subjects with unilateral upper extremity impairment, handling foods (level of dependence, 2.6), using a computer (2.9), cleaning (3.4), and self-exercise (3.4) showed high dependency.

Regarding the external robotic arm, handling foods (75.0\%, important or very important), using a computer $(75.0 \%)$, hairdressing $(70.8 \%)$, and using a smartphone $(66.7 \%)$ were considered objectively important and subjectively necessary functions. However, moving close items $(75.0 \%$, necessary or highly necessary) and dressing $(62.5 \%)$ were the most highly necessary functions, whereas their importance was relatively rated with lower priority. Assistance in brushing teeth $(37.5 \%$, not necessary or of little necessity), switch control (37.5\%), making phone calls (33.3\%), and eating (33.3\%) showed low necessity for external robotic arms.

Importance and necessity showed generally higher ratings regarding the upper limb exoskeleton. Handling foods ( $87.5 \%$, important or very important), self-exercise $(87.5 \%)$, transfer $(87.5 \%)$, and using a smartphone (83.3\%) were considered objectively important functions. Regarding necessity, handling foods $(75.0 \%$, necessary or highly necessary), self-exercise $(66.7 \%)$, moving close items $(75.0 \%)$, dressing $(66.7 \%)$, washing face $(66.7 \%)$, hairdressing $(66.7 \%)$, and using a smartphone $(66.7 \%)$ were rated high. Brushing teeth $(66.7 \%)$ and eating $(62.5 \%)$ were relatively rated high in necessity as compared with their low rank in importance. Switch control (37.5\%, not necessary or of little necessity), making phone calls $(37.5 \%)$, and wheelchair control (33.3\%) were functions that were considered not necessary for the exoskeleton. The detailed data of the UIG are shown in Table 2, and Figures 1 and 2. 
Table 2. Dependency, importance, and necessity for assistive robots in the unilateral impairment group $(n=24)$.

\begin{tabular}{|c|c|c|c|c|c|c|c|c|c|}
\hline \multirow{2}{*}{ ADL Item * } & \multirow{2}{*}{ Dependency $^{a}$} & \multicolumn{4}{|c|}{ External Robotic Arm } & \multicolumn{4}{|c|}{ Upper Limb Exoskeleton } \\
\hline & & Important $^{b}$ & Necessary $^{c}$ & Highly Necessary $^{d}$ & Not Necessary ${ }^{\mathrm{e}}$ & Important $^{b}$ & Necessary $^{c}$ & Highly Necessary ${ }^{\mathrm{d}}$ & Not Necessary ${ }^{\mathrm{e}}$ \\
\hline Handling foods & 2.6 & $75.0(1)$ & $70.8(2)$ & $33.3(4)$ & $20.8(11)$ & $87.5(1)$ & $75.0(1)$ & $45.8(3)$ & $16.7(13)$ \\
\hline Computer & 2.9 & $75.0(1)$ & $54.2(6)$ & $33.3(4)$ & $25.0(7)$ & $70.8(12)$ & $50.0(15)$ & $25.0(14)$ & $25.0(6)$ \\
\hline Cleaning & 3.4 & $45.8(11)$ & $41.7(11)$ & $16.7(10)$ & 20.8 (11) & $70.8(12)$ & $58.3(12)$ & $29.2(12)$ & $29.2(4)$ \\
\hline Self-exercise & 3.4 & - & - & - & - & $87.5(1)$ & $66.7(3)$ & $50(2)$ & $8.3(18)$ \\
\hline $\begin{array}{l}\text { Moving close } \\
\text { items }\end{array}$ & 3.5 & $62.5(6)$ & $75.0(1)$ & $37.5(2)$ & $25.0(7)$ & $79.2(7)$ & $75.0(1)$ & $33.3(11)$ & $20.8(11)$ \\
\hline Dressing & 3.5 & $54.2(9)$ & $62.5(3)$ & $41.6(1)$ & $16.7(14)$ & $79.2(7)$ & $66.7(3)$ & $54.2(1)$ & $12.5(16)$ \\
\hline Washing Face & 3.8 & $45.8(11)$ & $45.8(9)$ & $25(7)$ & $29.2(5)$ & $83.3(4)$ & $66.7(3)$ & $41.7(7)$ & $12.5(16)$ \\
\hline Transfer & 3.8 & - & - & - & - & $87.5(1)$ & $58.3(12)$ & 25 (14) & $25.0(6)$ \\
\hline Hairdressing & 3.8 & $70.8(3)$ & $58.3(4)$ & $37.5(2)$ & $20.8(11)$ & $79.2(7)$ & $66.7(3)$ & $45.8(3)$ & $16.7(13)$ \\
\hline Brushing teeth & 3.8 & $58.3(7)$ & $33.3(14)$ & $25(7)$ & $37.5(1)$ & $70.8(12)$ & $66.7(3)$ & $41.7(7)$ & $16.7(13)$ \\
\hline Phone calls & 3.8 & $58.3(7)$ & $37.5(13)$ & $16.7(10)$ & $33.3(3)$ & $79.2(7)$ & $37.5(18)$ & $16.7(17)$ & $37.5(1)$ \\
\hline Writing & 3.8 & $66.7(4)$ & $54.2(6)$ & $16.7(10)$ & $29.2(5)$ & $75.0(11)$ & $62.5(9)$ & $45.8(3)$ & $25.0(6)$ \\
\hline Wheelchair control & 3.9 & - & - & - & & $66.7(16)$ & $50.0(15)$ & $29.2(12)$ & $33.3(3)$ \\
\hline Purse & 4.0 & $54.2(9)$ & $50.0(8)$ & $25.0(7)$ & $25.0(7)$ & $66.7(16)$ & $54.2(14)$ & $25.0(14)$ & $25.0(6)$ \\
\hline Smartphone & 4.0 & $66.7(4)$ & $58.3(4)$ & $29.2(6)$ & $25.0(7)$ & $83.3(4)$ & $66.7(3)$ & $37.5(10)$ & $20.8(11)$ \\
\hline Switch control & 4.1 & $37.5(14)$ & 41.7 (11) & $16.7(10)$ & $37.5(1)$ & $58.3(18)$ & $45.8(17)$ & $16.7(17)$ & $37.5(1)$ \\
\hline Eating & 4.1 & $45.8(11)$ & $45.8(9)$ & $16.7(10)$ & $33.3(3)$ & $70.8(12)$ & $62.5(9)$ & $41.7(7)$ & $29.2(4)$ \\
\hline Toilet use & 4.3 & - & - & - & - & $83.3(4)$ & $62.5(9)$ & $45.8(3)$ & $25.0(6)$ \\
\hline
\end{tabular}

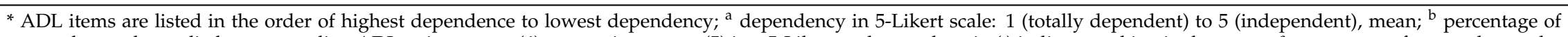
respondents who replied corresponding ADL as important (4) or very important (5) in a 5-Likert scale, numbers in ( ) indicate ranking in the group; ${ }^{\mathrm{c}}$ percentage of respondents who replied corresponding ADL as necessary (4) or highly necessary (5) in a 5-Likert scale, numbers in ( ) indicate ranking in the group; ${ }^{\mathrm{d}}$ percentage of respondents who replied corresponding ADL as highly necessary (5) in a 5-Likert scale, numbers in ( ) indicate ranking in the group; ${ }^{\mathrm{e}}$ percentage of respondents who replied corresponding ADL as not necessary (1) or of little necessity (2) in a 5-Likert scale, numbers in ( ) indicate ranking in the group. 


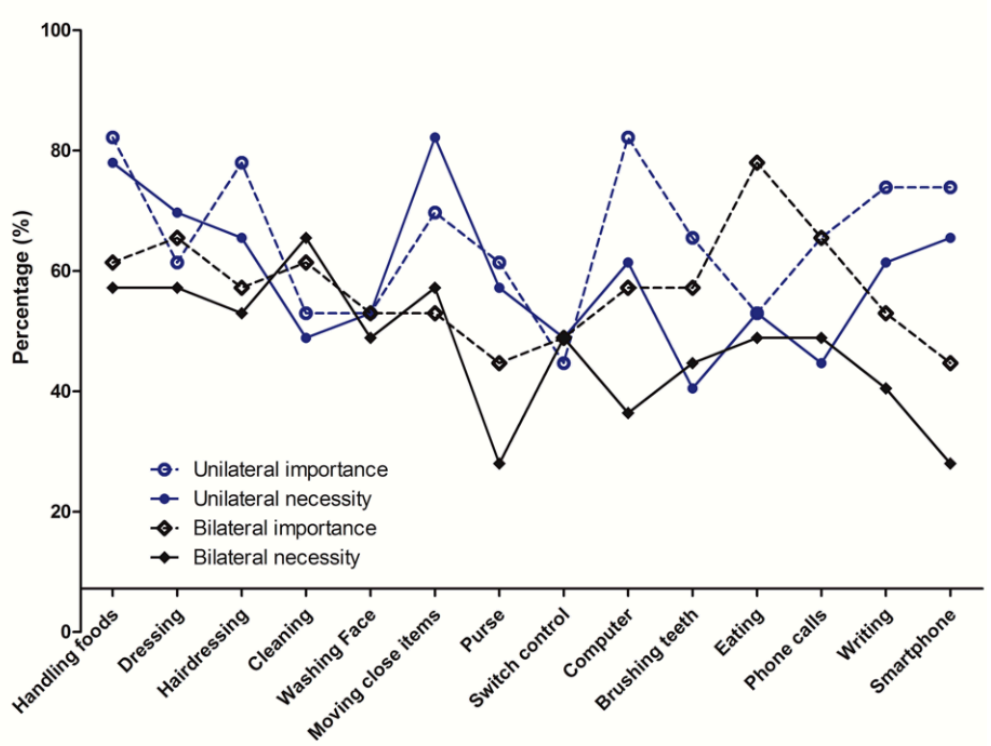

ADL items

Figure 1. The percentage of respondents who replied 'important' or 'very important' for importance (dotted line) and 'necessary' and 'highly necessary' for necessity (solid line) of an external robotic arm to each activity of daily living (ADL) function in each impairment group (unilateral impairment group: circle, bilateral impairment group: rhombus). The ADLs in the $x$-axis are in the order of high to low dependency for all survey participants.

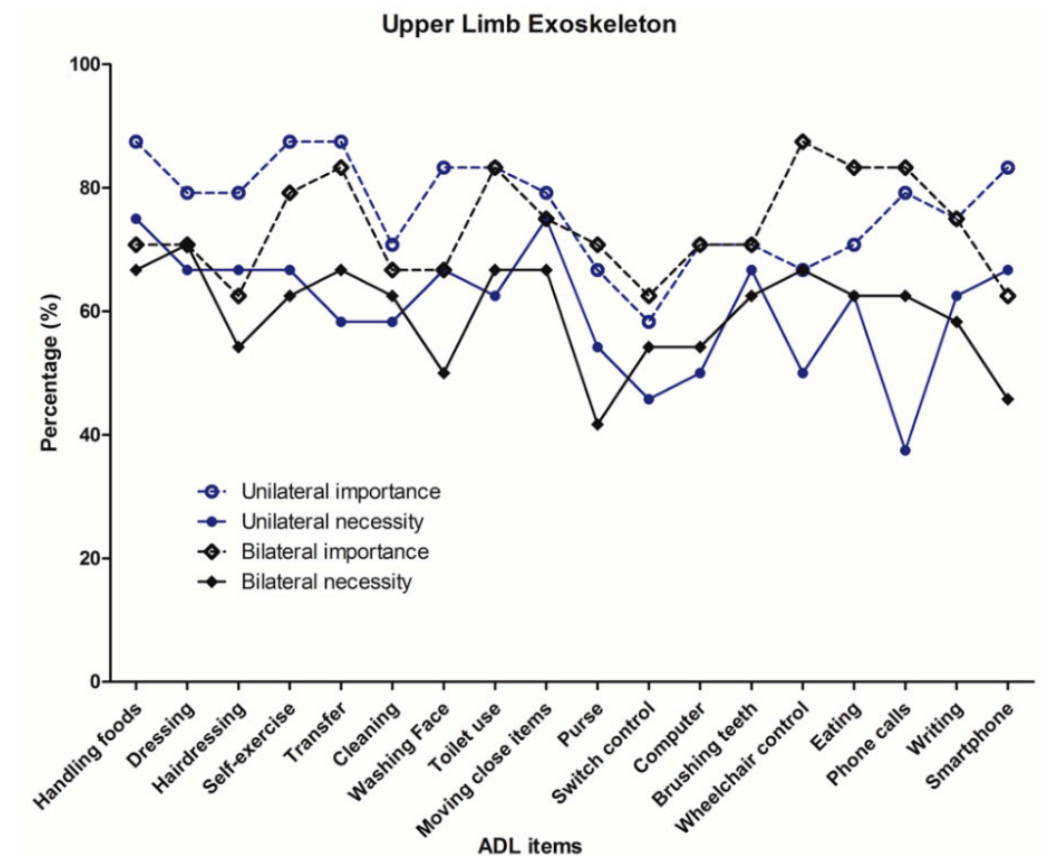

Figure 2. The percentage of respondents who replied 'important' or 'very important' for importance (dotted line) and 'necessary' and 'highly necessary' for necessity (solid line) of an upper limb exoskeleton to each ADL function in each impairment group (unilateral impairment group: circle, bilateral impairment group: rhombus). The ADLs in the $x$-axis are in the order of high to low dependency for all survey participants. 


\subsection{Bilateral Impairment Group}

The subjects with bilateral upper extremity impairment showed high dependency in toilet use (1.6), hairdressing (1.7), dressing (1.7), transfer (1.8), and handling foods (2.0). For an external robotic arm, assistance in eating $(70.8 \%$, percentage of being rated important or very important), dressing (58.3\%), making phone calls (58.3\%), handling foods (54.2\%), and cleaning (54.2\%) were considered important and necessary functions. Eating (33.3\%, percentage of being rated very necessary) and hairdressing $(33.3 \%)$ showed the highest percentage of being rated highly necessary functions for an external robotic arm. By contrast, using a smartphone ( $58.3 \%$, not necessary or of little necessity), purse $(54.2 \%)$, writing $(50.0 \%)$, and using a computer $(50.0 \%)$ showed low necessity for external robotic arms.

Importance and necessity regarding the upper limb exoskeleton also showed generally higher ratings in the BIG. Wheelchair control (important or very important, and necessary or highly necessary, respectively: $87.5 \%$ and $66.7 \%)$, transfer $(83.3 \%$ and $66.7 \%)$, toilet use $(83.3 \%$ and $66.7 \%)$, eating $(83.3 \%$ and $62.5 \%)$, phone calls $(83.3 \%$ and $62.5 \%)$, moving close items $(75.0 \%$ and $66.7 \%)$, dressing $(70.8 \%$ and $70.8 \%)$, handling foods $(70.8 \%$ and $66.7 \%)$, and self-exercise $(79.2 \%$ and $62.5 \%)$ showed both high importance and necessity. A high proportion of subjects replied writing (54.2\%) as a highly necessary function for the upper limb exoskeleton. Using a smartphone $(41.7 \%$, not necessary or of little necessity), washing face (37.5\%), using a purse (33.3\%), and using a computer (33.3\%) were considered less necessary functions for the exoskeleton. The detailed data for the BIG are shown in Table 3, and Figures 1 and 2.

\subsection{Unilateral Impaired Group vs. Bilateral Impaired Group}

For the external robotic arm, only necessity for smartphone use showed a significant difference between the UIG (mean, 3.4) and BIG (2.4, $p=0.037$, by the Mann-Whitney test). For the upper limb exoskeleton, only necessity for making phone calls showed a significant difference between the groups (UIG vs. BIG: 2.8 vs. 3.7, $p=0.043$ ), while the difference in necessity for wheelchair control showed borderline significance (3.1 vs. $4.1, p=0.052$ ).

\subsection{External Robotic Arm vs. Upper Limb Exoskeleton}

In most of the cases, upper limb exoskeletons demonstrated higher ratings in necessity than the external robotic arm. In the UIG, the upper limb exoskeleton showed significantly higher necessity in washing face ( 3.9 vs. $3.2, p=0.005$, by the Wilcoxon signed rank test), brushing teeth ( 3.8 vs. 3.0, $p=0.007)$, and eating (3.5 vs. 3.0, $p=0.009)$. In the BIG, significantly higher necessity for the upper limb exoskeleton was shown in dressing (4.0 vs. 3.4, $p=0.010)$, using a purse ( 3.2 vs. $2.5, p=0.045)$, switch control (3.5 vs. 3.1, $p=0.038)$, using a computer (3.4 vs. 2.7, $p=0.011)$, eating (3.5 vs. 3.0, $p=0.023$ ), making phone calls ( 3.7 vs. $3.0, p=0.026)$, writing ( 3.7 vs. $2.8, p=0.005)$, and using a smartphone (3.1 vs. $2.4, p=0.011$ ), while moving close items (3.8 vs. 3.4, $p=0.053$ ) showed borderline significance. 
Table 3. Dependency, importance, and necessity for assistive robots in the bilateral impairment group $(n=24)$.

\begin{tabular}{|c|c|c|c|c|c|c|c|c|c|}
\hline \multirow{2}{*}{ ADL Item * } & \multirow{2}{*}{ Dependency $^{a}$} & \multicolumn{4}{|c|}{ External Robotic Arm } & \multicolumn{4}{|c|}{ Upper Limb Exoskeleton } \\
\hline & & Important $^{b}$ & Necessary $^{c}$ & Highly Necessary ${ }^{\mathrm{d}}$ & Not Necessary ${ }^{\mathrm{e}}$ & Important $^{b}$ & Necessary $^{\mathrm{c}}$ & Highly Necessary ${ }^{d}$ & Not Necessary $^{\mathrm{e}}$ \\
\hline Toilet use & 1.6 & - & - & - & - & $83.3(2)$ & $66.7(2)$ & $45.8(4)$ & $16.7(12)$ \\
\hline Hairdressing & 1.7 & $50.0(6)$ & $45.8(5)$ & $33.3(1)$ & $16.7(14)$ & $62.5(16)$ & $54.2(13)$ & $33.3(12)$ & $16.7(12)$ \\
\hline Dressing & 1.7 & $58.3(2)$ & $50.0(2)$ & $29.2(3)$ & $29.2(11)$ & $70.8(9)$ & $70.8(1)$ & $45.8(4)$ & $12.5(14)$ \\
\hline Transfer & 1.8 & - & - & - & - & $83.3(2)$ & $66.7(2)$ & $58.3(1)$ & $25.0(8)$ \\
\hline Handling foods & 2.0 & $54.2(4)$ & $50.0(2)$ & $25.0(5)$ & $29.2(11)$ & $70.8(9)$ & $66.7(2)$ & $37.5(10)$ & $25.0(8)$ \\
\hline Washing Face & 2.0 & $45.8(9)$ & $41.7(6)$ & $12.5(13)$ & $33.3(8)$ & 66.7 (14) & $50.0(16)$ & $25.0(18)$ & $37.5(2)$ \\
\hline Self-exercise & 2.1 & - & - & & - & $79.2(6)$ & $62.5(7)$ & $41.7(7)$ & $8.3(18)$ \\
\hline Purse & 2.2 & $37.5(13)$ & $20.8(13)$ & $16.7(10)$ & $54.2(2)$ & $70.8(9)$ & 41.7 (18) & $33.3(12)$ & $33.3(3)$ \\
\hline Cleaning & 2.3 & $54.2(4)$ & $58.3(1)$ & $29.2(3)$ & $33.3(8)$ & $66.7(14)$ & $62.5(7)$ & $29.2(16)$ & 12.5 (14) \\
\hline Switch control & 2.3 & 41.7 (12) & $41.7(6)$ & $25.0(5)$ & $41.7(6)$ & $62.5(16)$ & $54.2(13)$ & $29.2(16)$ & $20.8(10)$ \\
\hline Moving close items & 2.4 & $45.8(9)$ & $50.0(2)$ & $12.5(13)$ & $20.8(13)$ & $75.0(7)$ & $66.7(2)$ & $33.3(12)$ & $12.5(14)$ \\
\hline Brushing teeth & 2.6 & $50.0(6)$ & $37.5(10)$ & $16.7(10)$ & $33.3(8)$ & $70.8(9)$ & $62.5(7)$ & $33.3(12)$ & $29.2(5)$ \\
\hline Eating & 2.8 & $70.8(1)$ & $41.7(6)$ & $33.3(1)$ & $45.8(5)$ & $83.3(2)$ & $62.5(7)$ & $41.7(7)$ & $29.2(5)$ \\
\hline Wheelchair control & 3.0 & - & - & - & - & $87.5(1)$ & $66.7(2)$ & $58.3(1)$ & 12.5 (14) \\
\hline Phone calls & 3.1 & $58.3(2)$ & $41.7(6)$ & $25.0(5)$ & $41.7(6)$ & $83.3(2)$ & $62.5(7)$ & $45.8(4)$ & $20.8(10)$ \\
\hline Writing & 3.1 & $45.8(9)$ & $33.3(11)$ & $16.7(10)$ & $50.0(3)$ & $75.0(7)$ & $58.3(12)$ & $54.2(3)$ & $29.2(5)$ \\
\hline Smartphone & 3.4 & 37.5 (13) & $20.8(13)$ & $20.8(8)$ & $58.3(1)$ & $62.5(16)$ & $45.8(17)$ & $37.5(10)$ & $41.7(1)$ \\
\hline Computer & 3.5 & $50.0(6)$ & $29.2(12)$ & $20.8(8)$ & $50.0(3)$ & $70.8(9)$ & 54.2 (13) & $41.7(7)$ & $33.3(3)$ \\
\hline
\end{tabular}

${ }^{*} \mathrm{ADL}$ items are listed in the order of highest dependence to lowest dependency; ${ }^{\mathrm{a}}$ dependency in 5-Likert scale: 1 (totally dependent) to 5 (independent), mean; ${ }^{\mathrm{b}}$ percentage of respondents who replied corresponding ADL as important (4) or very important (5) in a 5-Likert scale, numbers in ( ) indicate ranking in the group; ${ }^{\mathrm{c}}$ percentage of respondents who replied corresponding ADL as necessary (4) or highly necessary (5) in a 5-Likert scale, numbers in ( ) indicate ranking in the group; ${ }^{\mathrm{d}}$ percentage of respondents who replied corresponding necessity (2) in a 5-Likert scale, numbers in ( ) indicate ranking in the group. 


\section{Discussion}

Highly rated ADLs should be taken into consideration when designing a BMI-controlled robot for rehabilitation or ADL assistance, especially if the robot is going to be simple and portable, with selected functions. Several previous studies were conducted on the functional priorities of patients with specific diseases [18-20]. However, to our knowledge, this is the first study to assess the needs of potential users according to the type of robot and laterality of the impairment.

Chronic stroke patients with hemiplegia generally rated bimanual ADL as the most necessary functions for both types of robot. Nearly $80 \%$ of stroke patients with hemiplegia become able to perform most one-handed ADLs and several two-handed ADLs according to the degree of hemiparesis. All 24 stroke patients in this study also had hemiplegia and were able to use the unaffected arm properly. Therefore, ADLs that require both upper extremities were rated as the most necessary functions that a robot should provide. Handling foods, dressing, and hairdressing are functions that require both hands to perform. However, the most important and necessary function for the exoskeleton in stroke patients was self-exercise of the upper extremity, which had a higher score than the bimanual functions. The mean duration since stroke onset was about 110 months in our study population. Many of these chronic stroke patients had moderate to severe spasticity in major upper extremity joints. The rate of spasticity after stroke is reported to be approximately 30\% to $60 \%$ [21]. During a short interview after the survey, the participants stated that they would like to have an upper extremity robot that could help them exercise at home, in addition to the therapies that they receive in rehabilitation centers. It seems that personal robots with exercise functions would help patients continue their exercises at home to enhance functional recovery and decrease spasticity, which would increase patients' ADL performance level. Many studies have also reported that a decrease in spasticity leads to better ADL performance and a lower burden for care [22,23]. In addition, several studies showed greater functional improvement when robotic rehabilitation therapy was provided for up to 5 hours a day for 12 weeks than when a lesser treatment dose was used, which indicates that continuing exercise with robots throughout the day would result in better outcomes [24-26].

In the BIG, eating and hairdressing, as well as cleaning, handling foods, dressing, and moving close items, were ADLs that received relatively high scores for the necessity of external robotic arms. For the exoskeletons, dressing, toilet use, transfer, wheelchair control, moving close items, and handling foods showed high demands. A previous study in patients with amyotrophic lateral sclerosis (ALS) also showed that "using the bathroom" was among the highest priorities for a BMI in addition to communication and controlling motorized wheelchairs [20]. Self-exercise of the upper extremity also received high scores in both importance and necessity. This result is in agreement with previous studies, which found that patients with spinal cord injuries reported that restoration of walking and arm and hand functions along with bladder and bowel control were all high priorities, and that they would like to use a BMI system to control functional electrical stimulation in order to enhance functional recovery $[18,27]$. The patients in this study wanted to control the exoskeleton with a BMI system to perform their upper extremity exercises.

Figures 1 and 2 show the importance and necessity of each type of robot in both impairment subgroups. The ADLs in the $x$-axis are given in the order of level of dependency, from highly dependent to nearly independent. It is easily noticed that importance and necessity are not in proportion with dependency. The results shown in the figures indicated the ADLs that were considered important, but not actually necessary for everyday lives. In regard to both robot types, the UIG did not need to take phone calls or use computers with the robot. This may be because they have an intact arm and are older in age than the patients in other disease categories. For the exoskeletons, stroke patients did not require wheelchair control or transfer assistance, as they could manage it with their intact arm or by using a cane.

In general, the ratings for importance and necessity for the exoskeleton were higher than those for the external robotic arm. The UIG showed significantly higher necessity for the exoskeleton than for external robotic arms in washing face, brushing teeth, and eating. In the BIG, dressing, moving close 
items, using a purse, switch control, using a computer, eating, making phone calls, writing, and using a smartphone showed higher necessity for exoskeletons. While bimanual ADLs such as hairdressing, handling foods, and dressing showed high scores for both types of robot, the patients with unilateral impairment demonstrated higher demands for using exoskeletons for grooming-related activities, whereas the subjects with bilateral impairments tended to give higher scores to activities necessary for social functioning and interactions.

The primary purpose of this survey study was to assess pure potential users' unmet practical demands regardless of technical difficulties; therefore, we assumed that the device would be controlled perfectly by a BMI system. We also assumed that the simpler the robot, the more it would be feasible for patient application, and in order to be simple, the robot should perform limited tasks. The limited tasks should be the functions that the patients would really need, instead of useless functions. After deciding the target function, the design and development process should be focused on how will the robot can assist the ADL function most properly, controlled by user intent as much as possible, without interfering with basic activities. Therefore, the results of this study could also be applied to the robots not controlled by a BMI system. A specific control method or design should be selected on the basis of the target function. Workspace and motion analyses for performing such tasks should be assessed as well [28]. Tanaka et al. [29] suggested an ICF (International Classification of Functioning, Disability, and Health) based concept in developing and utilizing assistive robots for specific ADLs, which may guide the developmental process in the clinical perspective. Regarding the engineering aspects of the developmental process, Maciejasz et al. [1] reviewed up-to-date existing solutions for the development of upper limb rehabilitation robots regarding applications, type of assistance, design, and control methods.

This study has several limitations. First, the number of subjects was not sufficient to generalize the needs of all persons with upper extremity impairments. The subjects in the UIG were relatively homogeneous and representative of chronic stroke patients; however, the BIG mostly consisted of young patients with muscular dystrophy and only five patients with cervical spinal cord injuries, potentially possessing limitations for generalization. However, most previous studies were performed in patients with spinal cord injuries or ALS. Therefore, this study may provide a reference for comparison between different disease entities. Second, most of the participants were not familiar with the concept of a BMI other than the explanation given to them just before the survey. There may have been some difficulties in imagining how it would be with the given technology and functions. If they had known more about BMIs and rehabilitation robots, the survey results would have been more accurate.

\section{Conclusions}

The level of dependence and demand of potential BMI users differed according to the disease category, and also the type of end-effector robots. For practical use in the everyday lives of persons with disabilities, the robots for ADL assistance should be designed and developed considering real applications from the very beginning. The survey results from this study would guide and accelerate meeting end user needs in the development of assistive rehabilitation robots and BMI systems.

Author Contributions: Conceptualization, H.S.N., H.G.S., S.K. and M.S.B.; Data curation, J.-H.L. and Y.J.K.; Formal analysis, H.S.N.; Investigation, H.G.S. and S.K.; Resources, H.G.S. and M.S.B.; Supervision, J.-H.L., S.K. and M.S.B.; Visualization, H.S.N. and Y.J.K.; Writing—original draft, H.S.N., J.-H.L. and Y.J.K; Writing一review and editing, H.S.N., H.G.S., S.K. and M.S.B.

Funding: This research was supported by a grant (NRCTR-EX15002, NRCTR-EX16008) from the Translational Research Center for Rehabilitation Robots, Korea National Rehabilitation Center, Ministry of Health \& Welfare, Korea. This research was also supported by the Brain Research Program through the National Research Foundation of Korea (NRF) funded by the Ministry of Science, ICT \& Future Planning (2016M3C7A1904984).

Declaration: This manuscript is a revision of part of the first author's (Nam HS) Ph.D. thesis from Seoul National University.

Conflicts of Interest: The authors declare no conflict of interest. 


\section{Appendix A Survey for Potential Users' Demand on Assistive Robots.}

* This survey is to be performed by the examiner throughout the whole process to explain each questions and activities-of-daily living items, and ensure that the respondent is always aware of the rating scale.

0. Please check your gender and age: $\mathrm{M} / \mathrm{F} /$ Age:

1. Please check on the disease category that caused your impairment.

- 1) Stroke

- 2) Spinal cord injury

- 3) Muscular dystrophy

- 4) Motor neuron disease

- 5) Peripheral nerve injury

- 6) Others:

2. When was the onset of the impairment? Year Month years ago)

3. How well do you use your upper extremities?

- 1) I can use both arms functionally (at least partially)

- 2) I only use one arm functionally

- 3) I can hardly use both arms functionally

4. Please check on your gait status.

- 1) I can walk independently without any assistive tools.

- 2) I can walk independently using some assistive tools.

- 3) I need another person's assistance (regardless of assistive tool use)

- 4) I hardly can walk despite any kind of help from others.

5. Is a wheelchair your main method of moving? $\mathrm{Y} / \mathrm{N}$

* As you have been informed during your consent, please assume that the following robots (external robotic arm and upper limb exoskeleton: shown in pictures) may be controlled perfectly according to your intent, to perform the following activities-of-daily living tasks. Regarding each task, please reply about your 1) current dependence on others; your ratings on 2) objective importance of the function from the viewpoint of a developers based on your experience with severe functional impairment; and 3) subjective necessity of the function from the viewpoint of a consumers based on your current daily activities. For the subjective necessity, please think if you would use the function if a perfect robot was provided for the specific function. Please rate the objective importance and subjective necessity for the external robotic arm and upper limb exoskeleton separately.

Table A1. Ratings for dependence, importance, and necessity.

\begin{tabular}{llllll}
\hline 5-Likert Scale & \multicolumn{1}{c}{$\mathbf{1}$} & \multicolumn{2}{c}{$\mathbf{2}$} & $\mathbf{4}$ & $\mathbf{5}$ \\
\hline Dependence & Totally dependent & Mostly dependent & Moderately dependent & Mostly dependent & Totally dependent \\
\hline Importance & Unimportant & Of little importance & Moderately important & Important & Very important \\
\hline Necessity & Not necessary & Of little necessity & Moderately necessary & Necessary & Highly necessary \\
\hline
\end{tabular}


Table A2. Rating chart for each ADL items.

\begin{tabular}{|c|c|c|c|c|c|c|c|c|c|c|c|}
\hline \multirow{4}{*}{$\begin{array}{l}\text { ADL Items } \\
\text { Washing face }\end{array}$} & \multirow{3}{*}{$\begin{array}{l}\text { Dep } \\
\text { Imp }\end{array}$} & \multicolumn{5}{|c|}{ External Robotic Arm } & \multicolumn{5}{|c|}{ Upper Limb Exoskeleton } \\
\hline & & \multirow{2}{*}{$\begin{array}{l}1 \\
1\end{array}$} & \multirow[t]{2}{*}{2} & 3 & 4 & 5 & & \multirow[b]{2}{*}{2} & \multirow[b]{2}{*}{3} & \multirow[b]{2}{*}{4} & \multirow[b]{2}{*}{5} \\
\hline & & & & 3 & 4 & 5 & 1 & & & & \\
\hline & $\mathrm{Nec}$ & 1 & 2 & 3 & 4 & 5 & 1 & 2 & 3 & 4 & 5 \\
\hline \multirow{3}{*}{ Brushing teeth (including squeezing toothpaste) } & Dep & 1 & 2 & 3 & 4 & 5 & & & & & \\
\hline & $\operatorname{Imp}$ & 1 & 2 & 3 & 4 & 5 & 1 & 2 & 3 & 4 & 5 \\
\hline & $\mathrm{Nec}$ & 1 & 2 & 3 & 4 & 5 & 1 & 2 & 3 & 4 & 5 \\
\hline \multirow{3}{*}{ Hairdressing } & Dep & 1 & 2 & 3 & 4 & 5 & & & & & \\
\hline & Imp & 1 & 2 & 3 & 4 & 5 & 1 & 2 & 3 & 4 & 5 \\
\hline & $\mathrm{Nec}$ & 1 & 2 & 3 & 4 & 5 & 1 & 2 & 3 & 4 & 5 \\
\hline & Dep & 1 & 2 & 3 & 4 & 5 & & & & & \\
\hline Dressing (putting on or taking off clothes) & Imp & 1 & 2 & 3 & 4 & 5 & 1 & 2 & 3 & 4 & 5 \\
\hline 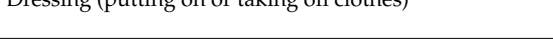 & $\mathrm{Nec}$ & 1 & 2 & 3 & 4 & 5 & 1 & 2 & 3 & 4 & 5 \\
\hline & Dep & 1 & 2 & 3 & 4 & 5 & & & & & \\
\hline Eating & $\operatorname{Imp}$ & 1 & 2 & 3 & 4 & 5 & 1 & 2 & 3 & 4 & 5 \\
\hline & $\mathrm{Nec}$ & 1 & 2 & 3 & 4 & 5 & 1 & 2 & 3 & 4 & 5 \\
\hline & Dep & 1 & 2 & 3 & 4 & 5 & & & & & \\
\hline Handling foods (i.e., peeling a banana, opening a & Imp & 1 & 2 & 3 & 4 & 5 & 1 & 2 & 3 & 4 & 5 \\
\hline & $\mathrm{Nec}$ & 1 & 2 & 3 & 4 & 5 & 1 & 2 & 3 & 4 & 5 \\
\hline & Dep & 1 & 2 & 3 & 4 & 5 & & & & & \\
\hline Cleaning (cleaning one's desk) & Imp & 1 & 2 & 3 & 4 & 5 & 1 & 2 & 3 & 4 & 5 \\
\hline & $\mathrm{Nec}$ & 1 & 2 & 3 & 4 & 5 & 1 & 2 & 3 & 4 & 5 \\
\hline & Dep & 1 & 2 & 3 & 4 & 5 & & & & & \\
\hline Moving close items & Imp & 1 & 2 & 3 & 4 & 5 & 1 & 2 & 3 & 4 & 5 \\
\hline & $\mathrm{Nec}$ & 1 & 2 & 3 & 4 & 5 & 1 & 2 & 3 & 4 & 5 \\
\hline & Dep & 1 & 2 & 3 & 4 & 5 & & & & & \\
\hline & $\operatorname{Imp}$ & 1 & 2 & 3 & 4 & 5 & 1 & 2 & 3 & 4 & 5 \\
\hline Smartphone (using a smartphone or a tablet) & $\mathrm{Nec}$ & 1 & 2 & 3 & 4 & 5 & 1 & 2 & 3 & 4 & 5 \\
\hline & Dep & 1 & 2 & 3 & 4 & 5 & & & & & \\
\hline Computer (using a computer: keyboard and mouse) & $\operatorname{Imp}$ & 1 & 2 & 3 & 4 & 5 & 1 & 2 & 3 & 4 & 5 \\
\hline & $\mathrm{Nec}$ & 1 & 2 & 3 & 4 & 5 & 1 & 2 & 3 & 4 & 5 \\
\hline & Dep & 1 & 2 & 3 & 4 & 5 & & & & & \\
\hline Making phone calls (dialing and receiving a phone call) & Imp & 1 & 2 & 3 & 4 & 5 & 1 & 2 & 3 & 4 & 5 \\
\hline & $\mathrm{Nec}$ & 1 & 2 & 3 & 4 & 5 & 1 & 2 & 3 & 4 & 5 \\
\hline & Dep & 1 & 2 & 3 & 4 & 5 & & & & & \\
\hline Writing & Imp & 1 & 2 & 3 & 4 & 5 & 1 & 2 & 3 & 4 & 5 \\
\hline & $\mathrm{Nec}$ & 1 & 2 & 3 & 4 & 5 & 1 & 2 & 3 & 4 & 5 \\
\hline & Dep & 1 & 2 & 3 & 4 & 5 & & & & & \\
\hline Switch control & $\operatorname{Imp}$ & 1 & 2 & 3 & 4 & 5 & 1 & 2 & 3 & 4 & 5 \\
\hline SW & $\mathrm{Nec}$ & 1 & 2 & 3 & 4 & 5 & 1 & 2 & 3 & 4 & 5 \\
\hline & Dep & 1 & 2 & 3 & 4 & 5 & & & & & \\
\hline Purse (putting in and taking out bills and cards from a & $\operatorname{Imp}$ & 1 & 2 & 3 & 4 & 5 & 1 & 2 & 3 & 4 & 5 \\
\hline purse/wallet) & $\mathrm{Nec}$ & 1 & 2 & 3 & 4 & 5 & 1 & 2 & 3 & 4 & 5 \\
\hline & Dep & 1 & 2 & 3 & 4 & 5 & & & & & \\
\hline Transfer (assisting bed to chair, chair to standing, etc.) & $\operatorname{Imp}$ & & & & & & 1 & 2 & 3 & 4 & 5 \\
\hline & $\mathrm{Nec}$ & & & & & & 1 & 2 & 3 & 4 & 5 \\
\hline & Dep & 1 & 2 & 3 & 4 & 5 & & & & & \\
\hline Toilet use & Imp & & & & & & 1 & 2 & 3 & 4 & 5 \\
\hline & $\mathrm{Nec}$ & & & & & & 1 & 2 & 3 & 4 & 5 \\
\hline & Dep & 1 & 2 & 3 & 4 & 5 & & & & & \\
\hline Self-exercise (of the upper extremity) & Imp & & & & & & 1 & 2 & 3 & 4 & 5 \\
\hline Self-exercise (or the upper extremity) & $\mathrm{Nec}$ & & & & & & 1 & 2 & 3 & 4 & 5 \\
\hline & Dep & 1 & 2 & 3 & 4 & 5 & & & & & \\
\hline Wheelchair control (both manual and electric) & Imp & & & & & & 1 & 2 & 3 & 4 & 5 \\
\hline 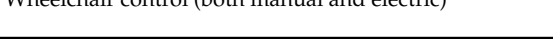 & $\mathrm{Nec}$ & & & & & & 1 & 2 & 3 & 4 & 5 \\
\hline
\end{tabular}

\section{References}

1. Maciejasz, P.; Eschweiler, J.; Gerlach-Hahn, K.; Jansen-Troy, A.; Leonhardt, S. A survey on robotic devices for upper limb rehabilitation. J. Neuroeng. Rehabil. 2014, 11, 3. [CrossRef] [PubMed]

2. Mehrholz, J.; Pohl, M.; Platz, T.; Kugler, J.; Elsner, B. Electromechanical and robot-assisted arm training for improving activities of daily living, arm function, and arm muscle strength after stroke. Cochrane Database Syst. Rev. 2015, 11, CD006876. [CrossRef] [PubMed] 
3. Maheu, V.; Frappier, J.; Archambault, P.S.; Routhier, F. Evaluation of the JACO robotic arm: Clinico-economic study for powered wheelchair users with upper-extremity disabilities. IEEE. Int. Conf. Rehabil. Robot. 2011, 2011, 5973597.

4. Sale, P.; Franceschini, M.; Mazzoleni, S.; Palma, E.; Agosti, M.; Posteraro, F. Effects of upper limb robot-assisted therapy on motor recovery in subacute stroke patients. J. Neuroeng. Rehabil. 2014, 11, 104. [CrossRef] [PubMed]

5. Klamroth-Marganska, V.; Blanco, J.; Campen, K.; Curt, A.; Dietz, V.; Ettlin, T.; Felder, M.; Fellinghauer, B.; Guidali, M.; Kollmar, A.; et al. Three-dimensional, task-specific robot therapy of the arm after stroke: A multicentre, parallel-group randomised trial. Lancet Neurol. 2014, 13, 159-166. [CrossRef]

6. Masiero, S.; Armani, M.; Ferlini, G.; Rosati, G.; Rossi, A. Randomized trial of a robotic assistive device for the upper extremity during early inpatient stroke rehabilitation. Neurorehabil. Neural Repair 2014, 28, 377-386. [CrossRef] [PubMed]

7. Mehrholz, J.; Elsner, B.; Werner, C.; Kugler, J.; Pohl, M. Electromechanical-assisted training for walking after stroke. Cochrane Database Syst. Rev. 2013, 7, CD006185.

8. Babaiasl, M.; Mahdioun, S.H.; Jaryani, P.; Yazdani, M. A review of technological and clinical aspects of robot-aided rehabilitation of upper-extremity after stroke. Disabil. Rehabil. Assist. Technol. 2016, 11, $263-280$. [CrossRef] [PubMed]

9. Lajeunesse, V.; Vincent, C.; Routhier, F.; Careau, E.; Michaud, F. Exoskeletons' design and usefulness evidence according to a systematic review of lower limb exoskeletons used for functional mobility by people with spinal cord injury. Disabil. Rehabil. Assist. Technol. 2015, 11, 535-547. [CrossRef]

10. Wall, A.; Borg, J.; Palmcrantz, S. Clinical application of the Hybrid Assistive Limb (HAL) for gait training-a systematic review. Front. Syst. Neurosci. 2015, 9, 48. [CrossRef]

11. Bedaf, S.; Gelderblom, G.J.; De Witte, L. Overview and Categorization of Robots Supporting Independent Living of Elderly People: What Activities Do They Support and How Far Have They Developed. Assist. Technol. 2015, 27, 88-100. [CrossRef] [PubMed]

12. Jarrasse, N.; Proietti, T.; Crocher, V.; Robertson, J.; Sahbani, A.; Morel, G.; Roby-Brami, A. Robotic exoskeletons: A perspective for the rehabilitation of arm coordination in stroke patients. Front. Hum. Neurosci. 2014, 8, 947. [CrossRef]

13. Collinger, J.L.; Wodlinger, B.; Downey, J.E.; Wang, W.; Tyler-Kabara, E.C.; Weber, D.J.; McMorland, A.J.; Velliste, M.; Boninger, M.L.; Schwartz, A.B. High-performance neuroprosthetic control by an individual with tetraplegia. Lancet 2013, 381, 557-564. [CrossRef]

14. Kwak, N.S.; Muller, K.R.; Lee, S.W. A lower limb exoskeleton control system based on steady state visual evoked potentials. J. Neural. Eng. 2015, 12, 056009. [CrossRef]

15. Kim, Y.J.; Park, S.W.; Yeom, H.G.; Bang, M.S.; Kim, J.S.; Chung, C.K.; Kim, S. A study on a robot arm driven by three-dimensional trajectories predicted from non-invasive neural signals. Biomed. Eng. Online 2015, 14, 81. [CrossRef] [PubMed]

16. Shah, S.; Vanclay, F.; Cooper, B. Improving the sensitivity of the Barthel Index for stroke rehabilitation. J. Clin. Epidemiol. 1989, 42, 703-709. [CrossRef]

17. Chumney, D.; Nollinger, K.; Shesko, K.; Skop, K.; Spencer, M.; Newton, R.A. Ability of Functional Independence Measure to accurately predict functional outcome of stroke-specific population: Systematic review. J. Rehabil. Res. Dev. 2010, 47, 17-29. [CrossRef] [PubMed]

18. Collinger, J.L.; Boninger, M.L.; Bruns, T.M.; Curley, K.; Wang, W.; Weber, D.J. Functional priorities, assistive technology, and brain-computer interfaces after spinal cord injury. J. Rehabil. Res. Dev. 2013, 50, 145-160. [CrossRef]

19. Huggins, J.E.; Moinuddin, A.A.; Chiodo, A.E.; Wren, P.A. What would brain-computer interface users want: Opinions and priorities of potential users with spinal cord injury. Arch. Phys. Med. Rehabil. 2015, 96, S38-S45.e5. [CrossRef]

20. Huggins, J.E.; Wren, P.A.; Gruis, K.L. What would brain-computer interface users want? Opinions and priorities of potential users with amyotrophic lateral sclerosis. Amyotroph. Lateral Scler. 2011, 12, 318-324. [CrossRef]

21. Watkins, C.L.; Leathley, M.J.; Gregson, J.M.; Moore, A.P.; Smith, T.L.; Sharma, A.K. Prevalence of spasticity post stroke. Clin. Rehabil. 2002, 16, 515-522. [CrossRef] [PubMed] 
22. Nam, H.S.; Park, Y.G.; Paik, N.J.; Oh, B.M.; Chun, M.H.; Yang, H.E.; Kim, D.H.; Yi, Y.; Seo, H.G.; Kim, K.D.; et al. Efficacy and safety of NABOTA in post-stroke upper limb spasticity: A phase 3 multicenter, double-blinded, randomized controlled trial. J. Neurol. Sci. 2015, 357, 192-197. [CrossRef] [PubMed]

23. Zorowitz, R.D.; Gillard, P.J.; Brainin, M. Poststroke spasticity: Sequelae and burden on stroke survivors and caregivers. Neurology 2013, 80, S45-S52. [CrossRef] [PubMed]

24. Daly, J.J.; Hogan, N.; Perepezko, E.M.; Krebs, H.I.; Rogers, J.M.; Goyal, K.S.; Dohring, M.E.; Fredrickson, E.; Nethery, J.; Ruff, R.L. Response to upper-limb robotics and functional neuromuscular stimulation following stroke. J. Rehabil. Res. Dev. 2005, 42, 723-736. [CrossRef] [PubMed]

25. Conroy, S.S.; Whitall, J.; Dipietro, L.; Jones-Lush, L.M.; Zhan, M.; Finley, M.A.; Wittenberg, G.F.; Krebs, H.I.; Bever, C.T. Effect of gravity on robot-assisted motor training after chronic stroke: A randomized trial. Arch. Phys. Med. Rehabil. 2011, 92, 1754-1761. [CrossRef] [PubMed]

26. McCabe, J.; Monkiewicz, M.; Holcomb, J.; Pundik, S.; Daly, J.J. Comparison of robotics, functional electrical stimulation, and motor learning methods for treatment of persistent upper extremity dysfunction after stroke: A randomized controlled trial. Arch. Phys. Med. Rehabil. 2015, 96, 981-990. [CrossRef] [PubMed]

27. Anderson, K.D. Targeting recovery: Priorities of the spinal cord-injured population. J. Neurotrauma 2004, 21, 1371-1383. [CrossRef] [PubMed]

28. Nam, H.S.; Lee, W.H.; Seo, H.G.; Kim, Y.J.; Bang, M.S.; Kim, S. Inertial Measurement Unit Based Upper Extremity Motion Characterization for Action Research Arm Test and Activities of Daily Living. Sensors 2019, 19, 1782. [CrossRef] [PubMed]

29. Tanaka, H.; Yoshikawa, M.; Oyama, E.; Wakita, Y.; Matsumoto, Y. Development of Assistive Robots Using International Classification of Functioning, Disability, and Health: Concept, Applications, and Issues. J. Robot. 2013, 608191, 1-12. [CrossRef]

(C) 2019 by the authors. Licensee MDPI, Basel, Switzerland. This article is an open access article distributed under the terms and conditions of the Creative Commons Attribution (CC BY) license (http://creativecommons.org/licenses/by/4.0/). 